\title{
METEOROLOGICAL NOISE IN WIRE STRAINMETER DATA FROM PARKFIELD, CALIFORNIA
}

\author{
By N. R. Goulty, P. M. Davis*, R. Gilman, and N. Motta
}

\begin{abstract}
Four invar-wire strainmeters have been operated in shallow trench sites for 19 months beside the San Andreas Fault at Parkfield, California. Temperature and rainfall records were correlated with $1 \mathrm{yr}$ of strainmeter data, and 90 per cent of the strain signal power at periods between 2 and 120 days was predicted entirely from these records, using a multi-channel, Wiener filtering technique. The residual strain series fluctuates with a peak-to-peak amplitude of nearly $10^{-6}$ strain. Anomalous strain signals taking place over several days would have to be larger than this to be identifiable. Previous work shows that signals of amplitude $10^{-7}$ strain are identifiable if they take place within hours. Deep creep events giving rise to such signals, which may occur as precursors to earthquakes, would need to be very large.

Other workers have shown that shallow, short-base line tiltmeters in California are also very sensitive to meteorological noise. Strainmeter and tiltmeter installations can be made less sensitive to meteorological noise, either by manufacturing instruments with long $(\sim 1 \mathrm{~km})$ base lines, or by using tunnel or borehole sites $(\geq 100 \mathrm{~m}$ deep). Proven instruments of these types are costly, unless an underground site was already available. However, if networks of shallow, shortbase line strainmeters or tiltmeters are to be used for earthquake prediction, it is obviously desirable to invest in at least a few installations which are less sensitive to noise of meteorological origin.
\end{abstract}

\section{INTRODUCTION}

One of the precursory phenomena postulated to occur before earthquakes is ground deformation. This could be caused by large, deep, preseismic creep events on the earthquake fault, which would give rise to detectable strain and tilt changes at the surface of the ground. Much interest has been generated by the data from the USGS shallow-borehole tiltmeter array in California. Anomalous tilt events have been reported as precursors to earthquakes, and were attributed to deep, preseismic creep events with moments approximately ten times greater than those of the subsequent earthquakes (Johnston and Mortensen, 1974; Mortensen and Johnston, 1976; Johnston et al., 1978). In a complementary experiment, four invar-wire strainmeters (King and Bilham, 1976) were installed in a broad, flat part of Cholame Valley on the Jack Ranch, Parkfield, California in May 1976 (Figure 1). Six Kinemetrics, biaxial, shallow-borehole tiltmeters of the type used in the USGS network were added in 1977, but only 3 months of data were obtained from them before all the instruments were knocked off-scale by the heavy rains commencing on December 27, 1977. Most of the instruments have since been relocated.

\section{Data and Discussion}

The strainmeters were each $18 \mathrm{~m}$ long and buried in trenches $1 \mathrm{~m}$ deep. The total span of 19-months data obtained from them is shown in Figure 2 with temperature and rainfall records from Paso Robles airport, $30 \mathrm{~km}$ away from the Jack Ranch in \footnotetext{
* Present address: Institute of Geophysics and Planetary Physics, University of California, Los Angeles,
California 90024.
} 
a direction $555^{\circ} \mathrm{W}$. The creep events noted on the strain records are of shallow origin and have already been analyzed in detail by Goulty and Gilman (1978). The plotted temperature record is a 5-day, unlagged, running average of daily maximum and minimum temperature values. This presentation was chosen because it allows (upward) temperature changes to be correlated with subsequent (extensional) apparent strain changes by eye. Daily cumulative amounts of rainfall were plotted, and the effect of rainfall can also be seen by visual inspection of the records. For example, apparent ground contraction on all four strainmeters followed the rains in early May 1977.

The tiltmeter data were at least an order of magnitude noisier than the strainmeter data, and obviously drifted in quite different directions, so they were not considered further. Although tilt and strain are not the same thing, both are dimensionless quantities representing a change in length divided by a base line length, so it is

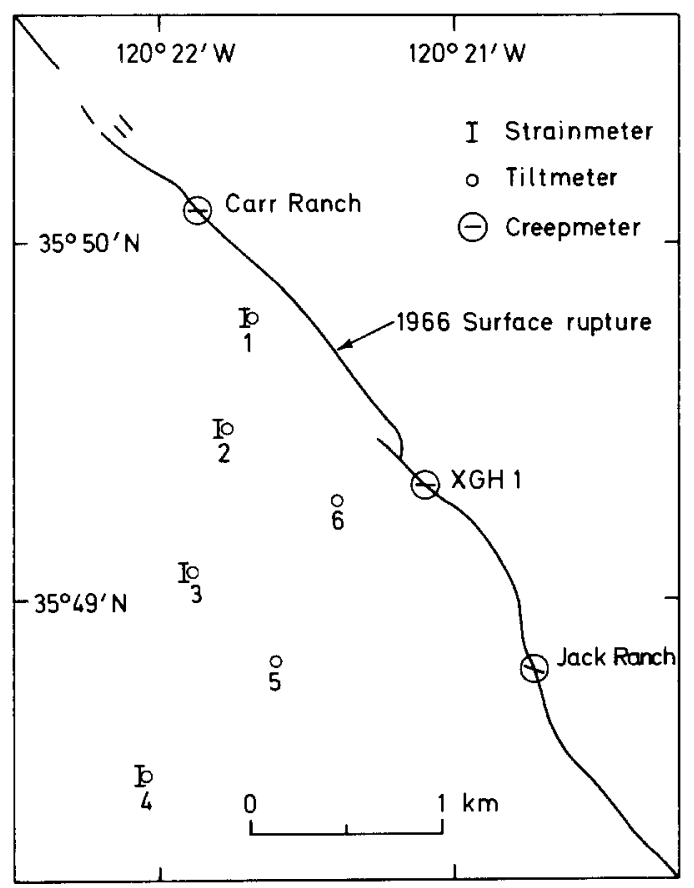

FIG. 1. Locations of the strainmeters and tiltmeters in Cholame Valley. The surface break associated with the 1966 Parkfield-Cholame earthquakes and the positions of three creepmeters are also shown.

reasonable to make rough comparisons of instrumental performance. The best tiltmeters in the USGS tiltmeter network produce data of better quality, more comparable to the strainmeter data presented here. The primary difficulty in installing any short-base line strainmeter or tiltmeter is in coupling the instrument to the ground without introducing a noise-amplifying inhomogeneity. Poor coupling also introduces "settling" noise. Variations in drift noise between our tiltmeters may be attributed to poor ground coupling rather than any defect in the hardware.

Because of the obvious correlation between the strain data and both temperature and rainfall, it was decided that this relationship should be analyzed further. One year of data from strainmeter 3, from July 15, 1976 to July 15, 1977 was chosen, as only 2 days of data were lost during that time. The strainmeter data were digitized at daily intervals. The rainfall time-series was composed of the daily cumulative amounts of rainfall, and daily values of temperature were taken from the unlagged, 
METEOROLOGICAL NOISE IN STRAINMETER DATA

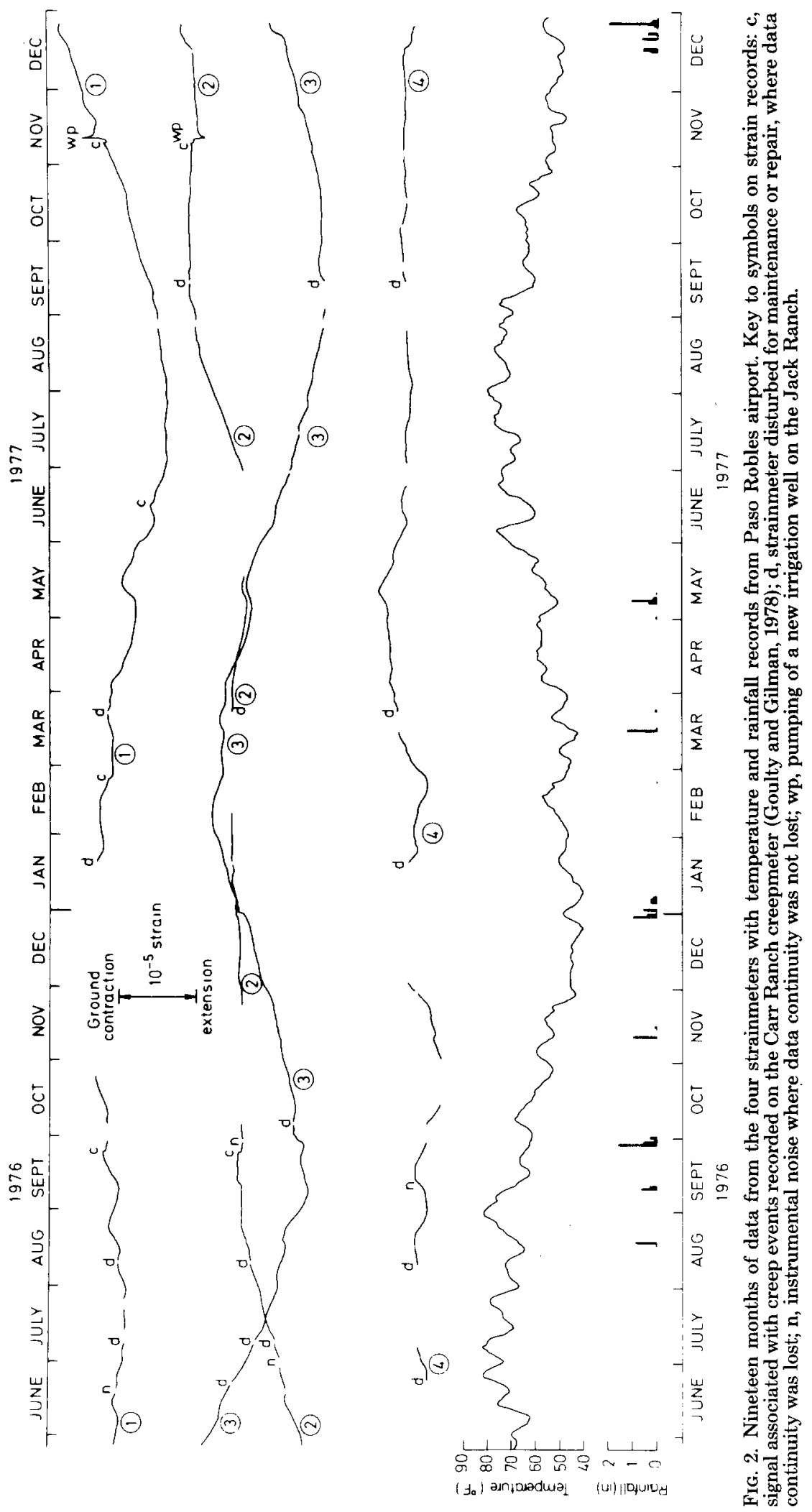


5 -day, running average of daily maximum and minimum temperatures. These timeseries are shown in Figure 2.

Wood and King (1977) filtered the effects of temperature and rainfall from shallow-borehole tiltmeter data sequentially, by a least-squares method. In a similar analysis, we used the multichannel, Wiener filtering program of Robinson (1967) to predict the power in the strain series attributable to both temperature and rainfall. This takes into acount any coherence between the two inputs, temperature and rainfall. All three series were prefiltered by removing all power at periods greater than 120 days.

The Wiener filtering method results in finding the linear filter which, when applied to one or more input series, provides the best fit to another observed series. The latter, in this case the strain series, is thus the desired series. The best fit is defined as being the filtered series which has the smallest root mean square error from the desired series. This filtered series is commonly described as the predicted series. The filter may be visualized as the combined impulse response to each input series. Thus, adding more filter coefficients allows for a more complex wave shape,

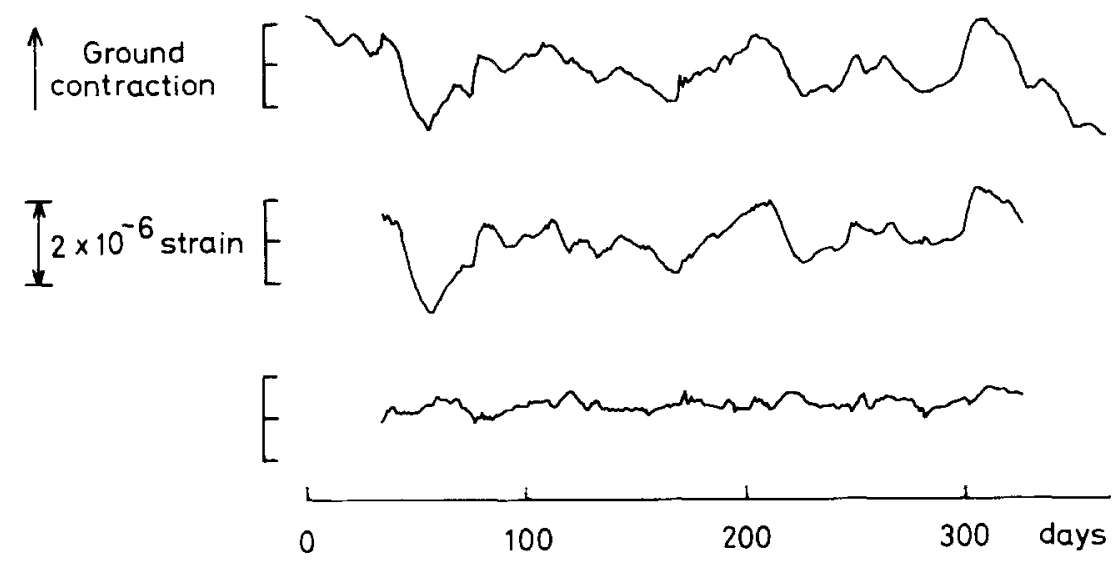

FIG. 3. Results of multichannel Wiener filtering. The raw strain, temperature and rainfall records were all prefiltered to remove signal at periods greater than 120 days. Top, initial strain series from strainmeter 3 over the period July 15,1976 to July 15, 1977; middle, strain signal predicted from temperature and rainfall; bottom, residual strain.

and therefore the capability of providing a better fit. In our case, using a filter of 150 coefficients, which was 75 days long as there were two input series, 90 per cent of the strain signal power was predicted. The results are shown in Figure 3. Adding further filter coefficients at this filter length only marginally improves the fit.

The filter was symmetrical about time zero: for rain or temperature signal on day 0 , the filter provides values for days -37 to -37 inclusive. Had all the series been random numbers, the predicted power would be expected to be around 43 per cent. The remaining 47 per cent may be taken as a measure of the correlation between the series. Calculation showed that the probability of predicting 90 per cent of the power with series of random numbers was much less than one in a million. As the filter length is one-fifth of the total data span and predicts 90 per cent of the power in the strain series over the whole period, we infer that the series are correlated and that the correlation is stationary. The rainfall record from Coalinga, slightly farther from Parkfield than Paso Robles airport, was also examined, and it showed rainfall on the same days as the Paso Robles record but in differing amounts. The response 
to rainfall, and possibly the response to temperature variations, may be expected to be nonlinear anyway. Accordingly, it is suggested that considerably more than half the power in the strain series is due to meteorological effects.

The residual strain series (Figure 3 ) is still substantially noisier than data from the $800 \mathrm{~m}$-long laser strainmeters at Piñon Flat (Berger and Levine, 1974). In the period range considered here, from 2 to 120 days, anomalous strain events would need to have amplitudes greater than about $10^{-6}$ strain to be identifiable. Smaller events could be identified if they took place more rapidly. For instance, the shallow creep events detected by these strainmeters gave strain signals of $3 \times 10^{-7}$ strain over $1 \mathrm{hr}$, which were well above the detection threshold (Goulty and Gilman, 1978). Large Californian earthquakes release strains of the order of $10^{-5}$, crudely estimated from the ratio of fault throw to fault length. The actual strains and tilts caused by a slip event on a fault will, of course, depend upon the position and dimensions of the dislocation loop as well as the position and orientation of the detecting instrument. However, in general we may conclude that shallow, short-base line strainmeters and tiltmeters could detect deep creep events with moments around 1 to 10 per cent of large earthquake moments, depending upon whether the events take place over hours or days. These would be very large creep events indeed. It remains to be proved that such events do occur, and how they might relate to subsequent earthquakes.

\section{CONCLUSIONS}

Our conclusions from these strainmeter data are similar to those drawn by Wood and King (1977) from tiltmeter data: the majority of the power in the strain data is of meteorological origin. In principle, it would be possible to filter the effects of temperature and rainfall from strain and tilt data with an on-line system, once the filters had been established. However, the response to rainfall seems likely to be nonlinear and to change with time. It would be preferable to install strainmeters and tiltmeters so that these effects were reduced in the first place.

This can be done in two ways. Temperature and rainfall noise in the ground of short wavelengths can be filtered out by making instruments with long base lines. Such installations must still be insensitive to the direct effect of temperature on the instrument hardware. The Piñon Flat laser strainmeters have been notably successful (Berger and Levine, 1974), but they are expensive. Liquid-filled tube tiltmeters are another possibility (Horsfall and King, 1978). The second alternative is to install strainmeters and tiltmeters in underground sites where the effects of temperature variations and rainfall are reduced (e.g., Bilham et al., 1974; installations used in the study by Beaumont and Berger, 1975). Tunnel sites are not widely available in California, but borehole instruments have been developed, e.g., the Sacks-Evertson borehole dilatometer (Sacks et al., 1975) and the Askania tiltmeter (Zschau, 1976). Short-base line installations of strainmeters and tiltmeters are always liable to have poor long-term drift rates, because of their small dimensions, but signals at annual periods can be measured more efficiently and extensively by geodetic techniques. The period range of interest for earthquake prediction, as far as strainmeters and tiltmeters are concerned, should be from hours to months.

The advantages of shallow, short-base line tiltmeters and strainmeters are cheapness and simplicity. But if they are to be widely deployed in networks for earthquake prediction because of cost restrictions, at least some higher quality installations, less sensitive to noise of meteorological origin, should be included. 


\section{ACKNOWLEDGMENTS}

This project was funded by USGS Contract 14-08-0001-16718. We thank the Hearst Corporation and Mr. Lorens Foard for permission to operate on the Jack Ranch. The computer programs used were established at Cambridge by R. J. Beavan, J. R. Evans, D. P. McKenzie, and A. M. Ziolkowski.

\section{REFERENCES}

Beaumont, C. and J. Berger (1975). An analysis of tidal strain observations from the United States of America: I. The laterally homogeneous tide, Bull. Seism. Soc. Am. 65, 1613-1629.

Berger, J. and J. Levine (1974). The spectrum of earth strain from $10^{-8} \mathrm{~Hz}$ to $10^{2} \mathrm{~Hz}$, J. Geophys. Res. 79, 1208-1214.

Bilham, R., G. King, and D. McKenzie (1974). Inhomogeneous tidal strains in Queensbury tunnel, Yorkshire, Geophys. J. 37, 217-226.

Goulty, N. R. and R. Gilman (1978). Repeated creep events on the San Andreas fault near Parkfield, California recorded by a strainmeter array, J. Geophys. Res. 83, 5415-5419.

Horsfall, J. A. C. and G. C. P. King (1978). A new geophysical tiltmeter, Nature 274, 675-676.

Johnston, M. J. S., A. C. Jones, W. Daul, and C. E. Mortensen (1978). Tilt near an earthquake $\left(M_{L}=\right.$ 4.3), Briones Hills, California, Bull. Seism. Soc. Am. 68, 169-173.

Johnston, M. J. S. and C. E. Mortensen (1974). Tilt precursors before earthquakes on the San Andreas fault, California, Science 186, 1031-1034.

King, G. C. P. and R. G. Bilham (1976). A geophysical wire strainmeter, Bull. Seism. Soc. Am. 66, 20392048.

Mortensen, C. E. and M. J. S. Johnston (1976). Anomalous tilt preceding the Hollister earthquake of November 28, 1974, J. Geophys. Res. 81, 3561-3566.

Robinson, E. A. (1967). Multichannel Time Series Analysis with Digital Computer Programs, HoldenDay, San Francisco.

Sacks, I. S., J. A. Snoke, Y. Yamagishi, and S. Suyehiro (1975). Borehole strainmeters-long-term stability and sensitivity to dilatancy, Carnegie Inst. Washington Yearbook 74.

Wood, M. D. and N. E. King (1977). Relative relation between earthquakes, weather and soil tilt, Science 197, 154-156.

Zschau, J. (1976). Tidal sea load tilt of the crust and its application, Geophys. J. 44, 577-593.

National CoAl Board

Hobart House

Grosvenor Place

LONDON SWIX 7AE ENGLAND (N.R.G.)

Seismological Laboratory

Division of Geological and Planetary Sciences

California INSTITUTE OF TECHNOLOGY

Pasadena, California 91125 (R.G. \& N.M.)

Contribution No. 3224
Manuscript received March 19, 1979

Department of Geodesy and Geophysics

Madingley Road

Cambridge CB3 OEZ England (P.M.D) 